\title{
Soil Fungi as Potential Source of Eco-Friendly Colorants
}

\author{
Carol Andrew Pereira*
}
P.G, Medical Laboratory technology, Department of Advance Zoology and Biotechnology, Loyola College, Chennai-600034, India

*Corresponding author

\begin{abstract}
A B S T R A C T
Keywords

Fungal pigments, Biocolorant,

Monascus, Fusarium spp, Alternaria spp, Trichoderma spp

Article Info

Accepted:

12 July 2019

Available Online:

10 August 2019

The primary objective of this study is to explore fungal pigments as a source for dyeing colorants. Owing to the conflicting reports on the safety of textile and leathers during dyeing and due to the indiscriminate use of non-permitted colors, there is an urgent need to identify natural pigment sources as safe textile colorant. This study critically examines the potentials of fungi as sources production of biocolorant. Along with an established pigment producing fungus, Monascus, newer fungi have been explored and reported. Soil samples from across the various agricultural soils were collected, pigment producing fungi were isolated and characterized. In addition to $\mathrm{M}$. purpureus, potent pigment producing fungal isolates such as Alternaria spp, Fusarium spp, Aspergillus spp and Trichoderma $s p p$ were studied to optimize the production technology for pigments. Further, the pigment fractions were analyzed using HPLC, GC-MS and NMR for structure prediction and were found to be anthraquinone (Alternaria spp), di-o-acetyl-lanugon-j (Fusarium spp), Heptacosonic acid 25-methyl ester (Aspergillus spp) and Chrysanthemum hydrolyzed (Tichoderma spp).Compounds which were produced by cultures of $M$. purpureus, Alternaria spp, Fusarium spp, Aspergillus spp and Trichoderma spp could be used for dyeing cotton with good fastness properties and high dye uptake. Our study showed that natural pigments dyes can provide bright hues and colour fastness properties. They can serve as a noteworthy source of raw material in the future.
\end{abstract}

\section{Introduction}

The textile industry produces and uses approximately 1.3 million tonnes of dyes, pigments and dye precursors, valued at around \$23 billion, almost all of which is manufactured synthetically (Sengupta and Singh. 2003; Francis, 1987). However, synthetic dyes have some limitations, primarily, (i) their production process requires hazardous chemicals, creating worker safety concerns, (ii) they may generate hazardous wastes, and (iii) these dyes are not environment friendly. This research explores methods where natural dyes are produced from plant tissue and fungal species (Diana $e t$ al., 2005). Until the second half of the nineteenth century, all dyes used in textiles were naturally derived. However, with the synthesis of mauveine by Perkin in 1856, the synthetic dye industry has grown at a vigorous rate and all but totally eradicated the use of natural dyes. The large number of synthetic dyes in use today bears witness to the 
creativity and innovation of textile chemists in successfully satisfying the dyer's demands for simple, reproducible application processes, and the consumer's demand for quality products at a reasonable price. Thus, the reasons synthetic dyes have been so popular are: simple to produce in large quantities; manufactured at a reasonable price $(\$ 10-$ $100 / \mathrm{kg}$ ); provide the variety of colors for today's consumers; high color-fastness (Hamlyn, 1995).

However, manufacturing of synthetic dyes suffers from the following limitations: Environmentally Unfriendly; Increase in Cost of Feedstock or Energy; Hazardous Waste Generation; Increasing Transportation Costs; Toxic and Allergic Reactions (Duran et al., 2002). Thus, if bioengineered natural, 'green' dyes can be produced at a comparable price, the pre-stated limitations can be overcome. The major avenues of production of "green" dyes are: Extraction from plants-Extraction from arthropods and marine invertebrates (e.g., sea urchins and starfish)-Extraction from algae (e.g., blue-green algae) Regardless of the source, it is believed that products which may be harnessed as "green" dyes are in essence secondary metabolites produced by the organism. These secondary metabolites are low molecular weight natural products that have a restricted taxonomic distribution, possess no obvious function in cell growth and are synthesized for a finite period by cells that are no longer undergoing balanced growth. However, they have specialized survival functions in nature and are observed to be numerous in organisms occupying densely inhabited environments and are believed to have a prominent role in the coexistence and coevolution of species allowing interaction within a community.

An effective biotechnology solution to manufacture of these and other dyes or dyestuff Intermediates will impart the following benefits: The medium in which these plant cells or fungi or bacteria grow contain no expensive or toxic chemicals-The process is carried out at low temperature (around $30^{\circ} \mathrm{C}$ ) compared to the fuelconsuming very high temperatures in the synthetic process-The process is typically run at neutral $\mathrm{pH}$ as opposed to very high acidic or alkaline conditions in the synthetic process.The process is very "environmentally friendly" and "sustainable" (Taylor, 1986). However, the key factors are; high yield of the product and high purity (Sukalyan Sengupta and Bal Ram Singh, 2003). Significance of the study is that Microbial dyes have some advantages over plant and animal based dyes as microbes are fast growing and have the potential of being standardized commercially. Microbial dyestuffs produce rare colour ideas and are automatically harmonizing. Unlike, non-renewable basic raw materials for synthetic dyes, these natural dyes are usually renewable and biodegradable and generally have a higher compatibility with the environment than synthetic dye therefore, no disposal problem of this natural waste (Patnaik et al., 1997).

\section{Materials and Methods}

Soil samples were collected across the various agricultural fields. Samples were collected in sterile polyethylene bags stored in an icebox and transported to the laboratory. Plating was done within $6 \mathrm{hrs}$ of collection of samples. Isolation of pigment producing fungi from soil samples (Warcup, 1950)- Fungi displaying intense attractive bright colors were further transferred to fresh PDA medium and confirmed for its color production. Purification of pigment producing fungal isolates by Single Hyphal Tip method (Mundkur, 1959)- After incubation for two days at room temperature $\left(28 \pm 2{ }^{\circ} \mathrm{C}\right)$, the colonies were observed for hyphal developments. Peripheral tip of the mycelial 
growth was taken from the plates, reinoculated to PDA medium and confirmed for the production of pigment. These purified colonies were transferred to PDA slants and stored. One set was used for further study Identification of fungi by moist chamber technique (Cappucino and Sherman, 1996) the isolates of fungi were grown on glass slides placed in petri dish moist chambers. The coverslip was carefully removed with fungal mycelium and a drop of lactophenol cotton blue stain (Jensen, 1931) and analysed further. These slides were examined under microscope and the different features of the fungi were noted. Manuals carrying the description of fungi were consulted for identification (Gi1man, 1957; Barnett, 1958; Dennis, 1968; Ainsworth et al., 1973: Alexopolous, 1988). For further confirmation the culture was identified at Mycology and Plant Pathology Laboratory, Agharkar Research Institute, Pune. Among the pigment producing fungal isolates, Alternaria spp, Fusarium spp, Aspergillus spp and Trichoderma spp obtained from the agricultural soils were found to be potent. These isolates were selected for further study. These were compared with the reference strain Monascus purpureus MTTC 410 which was used as standard strain. Selection of agar medium: Purified selected fungal cultures were grown on different agar media Maximum pigment production was found in Czapek- Dox broth medium, when compared to other liquid media. Further studies were carried out in this medium. Monascus spp. (Reference strain) from Mycology and Plant Pathology Laboratory, Agharkar Research Institute, Pune.

Production of pigment by selected fungal isolates was performed by Lin and lizuka, 1982 method. The following four isolates viz., Alternaria spp, Fusarium spp, Aspergillus spp and Trichoderma spp were selected on the basis of high pigment production for further studies. Besides these isolate the standard strain, Monascus purpureus 410 was also used. Factors which might influence pigment production like $\mathrm{pH}$ of the medium, agitation, temperature, carbon, nitrogen and light sources were studied. Pigments were extracted following two methods; Extraction using solvents and Pigment recovery by air-drying. Physical and chemical properties of the pigments were studied (Lee and Chen, 1998). The clear supernatant was collected for analysis and characterized by spectrophotometry-The samples were scanned for their maximum absorbance at different wavelengths in a (Hitachi-3210 UV-Vis) spectrophotometer from $200 \mathrm{~nm}$ to $700 \mathrm{~nm}$. The maximum absorbance at different wavelengths was recorded. Column Chromatography study: The crude extract of the air-dried color pigment powder was subjected to fractionation by Column chromatography, Elutes were collected and detected using UV absorption (300 and 500 $\mathrm{nm})$. Thin layer chromatography of the pigments (Blanc et al., 1994) Individual spots on the TLC plates were marked and $\mathrm{R}_{\mathrm{f}}$ values calculated. Each spot was collected from the plates and stored in a clean glass vial. High Performance Liquid Chromatography (HPLC) (Blanc et al., 1994) the bands recovered from the TLC plates was used to extract pigments in $10 \mathrm{ml}$ of methanol. Free and complex pigments were analyzed by using HPLC on a C18 column by using the following linear separation solvents of 80:20 (v/v) (methyl alcohol: water). The analysis were performed with a Hewlett-Packard 1090 Series II liquid chromatograph equipped with a photodiode array detection system, using a LiChrospher 100 RP-18 analytical column (5 corremm; $12534.0 \mathrm{~mm}$; Merck, Darmstadt, Germany) at $40.8^{\circ} \mathrm{C}$. The mobile phase consisted of a twostep gradient of $0.085 \%(\mathrm{v} / \mathrm{v})$ aqueous. Gas Chromatography-Mass Spectrum-Residue was dissolved in $400 \mathrm{ml}$ methanol ultrasonicated for $10 \mathrm{~min}$, and filtered through 0.45-ml PTFE syringe filter (SRI, Eatontown, NJ, USA). 
Infrared spectrum- the dried crystal of the new red pigment was scanned by a Bio-Rad FES135 infrared spectrometer using $\mathrm{KBr}$ method at $27^{\circ} \mathrm{C}$.

\section{Results and Discussion}

Soil samples were collected in sterile polyethylene bags from Agricultural fields and. The samples were subjected for the enumeration of total and pigment producing fungal colonies and the results are presented in Table 1. Total fungal colonies of the soil samples ranged from $4.2 \times 104$ to $26.2 \mathrm{cfu} / \mathrm{g}$ of soil. Among the various soil samples paddy Rhizosphere (PR) showed the maximum (26.2 x $104 \mathrm{cfu} / \mathrm{g}$ ) fungal count followed by teak tree Rhizosphere (TTR) (26.1 x $104 \mathrm{cfu} / \mathrm{g})$, Supari field Rhizoshpere(SFr) $(26.0 \times 104$ $\mathrm{cfu} / \mathrm{g}$ ), Vegetable field location-1 (VFL-1) $(24.2 \times 104 \mathrm{cfu} / \mathrm{g})$. Fungal colony count was less in soil sample collected from arid lands which was 4.2 x $104 \mathrm{cfu} / \mathrm{g}$. The Monascus purpureus obtained from Agarkar Institue, Pune, was used as reference strain for the study.

Agar media like Potato dextrose agar (PDA), Czapek-Dox agar (CDA), Mycological agar (MA), Yeast morphology agar (YMA), Sabouraud dextrose agar (SDA), Martin Rose Bengal Agar (RBA), Malt extract agar (MEA) and Monascus agar (MAM) were used to study the influence of agar media on the growth and pigment production of selected four fungal species. Among the agar media used, maximum growth and pigmentation $(+++)$ of all the isolates were observed in PDA medium. The growth and pigmentation of $M$. purpureus (reference strain) was good (+++) in Sabouraud dextrose agar and Monascus agar medium. Czapek-Dox agar medium supported moderate growth $(++)$ with good pigmentation (+++) of all the isolates. Various broth media like Potato Dextrose broth, Czapek-Dox broth, Mycological broth, Yeast morphology broth, Sabouraud Dextrose broth, Martin Rose Bengal broth, Malt extract broth and Monascus broth were used to study the influence of broth media on the biomass and pigment production of above selected fungal species and the results are presented in Table 2. Among the broth media used, good biomass and pigmentation of all the isolates were noticed in Czapek-Dox broth medium (plate $2)$. The growth and pigmentation of $M$. purpureus (reference strain) was good (+++) in Czapek-Dox broth, malt extract broth and Monascus broth medium. Effect of $\mathrm{pH}$ on the biomass production in $\mathrm{pH} 6$ the maximum biomass of $6.56 \mathrm{~g} / \mathrm{l}, 4.7 \mathrm{~g} / \mathrm{l}$, and $5.46 \mathrm{~g} / \mathrm{l}$ were recorded in $M$. purpureus, Trichoderma.spp and Fusarium spp after 5 days of incubation respectively (Table 2). The other two isolates, Alternaria.spp and Aspergillus spp showed higher biomass production at $\mathrm{pH}$ 5. Other $\mathrm{pH}$ tested was not encouraging the growth of the isolates.

The influence of various temperatures $\left(20^{\circ} \mathrm{C}\right.$, $28^{\circ} \mathrm{C}$ and $37^{\circ} \mathrm{C}$ ) on the production of biomass, intracellular and extracellular pigment production of fungal isolates was studied and the results are given. The influence of temperature on biomass production is given in Table 3. The incubation temperature of $28^{\circ} \mathrm{C}$ increased the biomass of all the four fungal isolates. Among the four fungal isolates Alternaria spp showed maximum biomass at $28^{\circ} \mathrm{C}$, however it was less than the results shown by M. purpureus.

The biomass production of $M$. purpureus was $5.5 \mathrm{~g} / \mathrm{l}$, followed by Alternaria spp $(4.42 \mathrm{~g} / \mathrm{l})$, Trichoderma spp (4.12 g/l), Fusarioum (3.36 $\mathrm{g} / \mathrm{l})$ and Aspergillus spp $(3.14 \mathrm{~g} / \mathrm{l})$ at $28^{\circ} \mathrm{C}$. Biomass production at $20^{\circ} \mathrm{C}$ was maximum in Fusarium spp $(3.96 \mathrm{~g} / \mathrm{l})$ and at $37^{\circ} \mathrm{C}$ the biomass of all isolates were comparatively less with other incubation temperature. From the result it was observed that room temperature $\left(28 \pm 2^{\circ} \mathrm{C}\right)$ appeared to be optimum for the 
growth of all the selected fungi. Low temperature $\left(20^{\circ} \mathrm{C}\right)$ and higher temperature $\left(37^{\circ} \mathrm{C}\right)$ reduced the biomass yield. Effect of various carbon sources (sucrose, glucose, maltose, galactose, fructose, lactose, starch and ethanol) on the biomass production, intracellular and extracellular pigment production were studied and the results are shown in Table 4. The biomass of $M$. purpureus was found to be maximum (7.68 $\mathrm{g} / \mathrm{l})$ in the medium supplemented with sucrose followed by glucose $(7.34 \mathrm{~g} / \mathrm{l})$ at 5 days. In, galactose, mannitol, fructose, ethanol, starch, lactose, maltose, the biomass production showed about $7.20 \mathrm{~g} / 1$ to $1.12 \mathrm{~g} / \mathrm{l}$. The results showed that sucrose was an ideal carbon source favoring the biomass production of the fungi $M$. purpureus, sucrose and glucose were ideal sources for Alternaria spp, Trichoderma spp, Fusarium spp and Aspergillus spp respectively. Trichoderma spp was recorded in $6 \%$ concentration of sucrose and the minimum $\left(78.2 \mathrm{U} / \mathrm{ml}^{-1}\right)$ in $1 \%$ sucrose. Whereas in the medium containing sucrose concentration at 2 , 3,4 and $5 \%$ the pigment recorded were about $120.1 \mathrm{U} / \mathrm{ml}^{-1}, 112.2 \mathrm{U} / \mathrm{ml}^{-1}, 102 \mathrm{U} / \mathrm{ml}^{-1}$ and 98 $\mathrm{U} / \mathrm{ml}^{-1}$ respectively. The higher concentration of Aspergillus spp, Fusarium spp, Alternaria spp and M. purpureus were $62.2 \mathrm{U} / \mathrm{ml}-1,93.0$ $\mathrm{U} / \mathrm{ml}-1, \quad 75.0 \mathrm{U} / \mathrm{ml}-1$ and $42.4 \mathrm{U} / \mathrm{ml}-$ 1respectively.The extracellular pigment production of fungi in the medium supplemented with various concentration of sucrose $(1,2,3,4,5,6$ and 7\%) was estimated.

In general the maximum pigment productions of all the fungi were recorded in $6 \%$ followed by $5 \%$ sucrose concentration. The maximum pigment production of $126 \mathrm{U} / \mathrm{ml}-1$ in Trichoderma spp was recorded in $6 \%$ concentration of sucrose and the minimum (78.2 $\mathrm{U} / \mathrm{ml}-1)$ in $1 \%$ sucrose. Whereas in the medium containing sucrose concentration at 2 , 3,4 and $5 \%$ the pigment recorded were about $120.1 \mathrm{U} / \mathrm{ml}-1,112.2 \mathrm{U} / \mathrm{ml}-1,102 \mathrm{U} / \mathrm{ml}-1$ and
98 U/ml-1 respectively. The higher concentration of Aspergillus spp, Fusarium spp, Alternaria spp and $M$. purpureus were $62.2 \mathrm{U} / \mathrm{ml}-1,93.0 \mathrm{U} / \mathrm{ml}-1,75.0 \mathrm{U} / \mathrm{ml}-1$ and $42.4 \mathrm{U} / \mathrm{ml}-1$ respectively.

The data on the effect of different wavelength of light on growth and pigment production in fungi are presented in Table 5. Darkness has induced the production. Among the isolates $M$. purpureus was leading in biomass production of $7.46 \mathrm{~g} / \mathrm{l}$, followed by Alternaria spp 7.26 $\mathrm{g} / 1,7.17 \mathrm{~g} / \mathrm{l}$ by Aspergillus spp and $6.71 \mathrm{~g} / \mathrm{l}$ Trichoderma spp. The minimum quantity of biomass was yielded by Fusarium spp as $5.26 \mathrm{~g} / \mathrm{l}$ of biomass in darkness. White light induced the production of biomass however it was low when compared to darkness. At the same time, Fusarium spp showed maximum growth in mixed unscreened light than darkness. Green light induced the growth of all the fungal isolates. The maximum biomasses of all the isolates were recorded when grown under green light. Table 5 illustrates the effect of different lights on the production of fungal biomass. Under unscreened white light and darkness all the five fungi produced the highest biomass. Under red, yellow, green and blue light, the biomass yield was comparatively low.

Except Fusarium spp, all the isolates exhibited maximum pigment production. Alternaria spp exhibited maximum of $68.2 \mathrm{U} / \mathrm{ml}-1$ followed by MP $66.75 \mathrm{U} / \mathrm{ml}-1$, Trichoderma spp 59.2 U/ml-1, Fusarium as $58.8 \mathrm{U} / \mathrm{ml}-1$ and Aspergillus spp $56.9 \mathrm{U} / \mathrm{ml}-1$. White light effected the maximum production of 64.9 U/ml-1 by $M$. purpureus followed by 63.9 U/ml-1 by Alternaria spp and the Fusarium spp in the concentration of $59.7 \mathrm{U} / \mathrm{ml}-1$. Nearly other two fungi Aspergillus spp and Trichoderma spp produced the minimum quantity of pigment (56.9 and $55.6 \mathrm{U} / \mathrm{ml}-1$ ). Green light supported Alternaria spp to produce maximum pigment concentration of 
$56.9 \mathrm{U} / \mathrm{ml}-1$ followed by $M$. purpureus as $55.02 \mathrm{U} / \mathrm{ml}-1$. The minimum quantity of 32.55 $\mathrm{U} / \mathrm{ml}-1$ of pigment was produced by Aspergillus spp. In blue light Alternaria spp produced the maximum amount of pigment (56.0 U/ml-1) followed by the concentration of $54.7 \mathrm{U} / \mathrm{ml}-1$ produced by $M$. purpureus, Trichoderma spp produced a moderate amount of pigment as $45.7 \mathrm{U} / \mathrm{ml}-1$. Yellow light served Alternaria spp to produce the maximum quantity of pigment as $47.63 \mathrm{U} / \mathrm{ml}-$ 1. A moderate amount concentration of pigment $29.75 \mathrm{U} / \mathrm{ml}-1$ was recorded in Fusarium spp and the least amount of 24.9 U/ml-1 was recorded by Aspergillus spp. Red light did not support much for the intracellular pigment production as a maximum pigment concentration was recorded in Trichoderma spp (39.50 U/ml-1) followed by $M$. purpureus (35.35 U/ml-1). The minimum concentration (19.1 U/ml-1) was recorded in Aspergillus spp. It was interesting from the data that intracellular pigments accumulated in the fungi significantly higher in darkness and unscreened white light.

Blue light and green light caused a reduction in pigment production, followed by yellow and red lightSix sources of light were used and the darkness induced the maximum pigment production followed by white light (unscreened light) in all the isolates. The maximum of $680.5 \mathrm{U} / \mathrm{ml}-1$ of pigment concentration was produced by Alternaria spp followed by the $M$. purpureus (658 U/ml-1) concentration. The minimum amount (491.5 U/ml-1) of pigment was seen in Fusarium spp. In white light, about $601 \mathrm{U} / \mathrm{ml}-1$ of pigment production was exhibited by Alternaria spp followed by $M$. purpureus $(548.5 \mathrm{U} / \mathrm{ml}-1)$ and Aspergillus spp (492 U/ml-1). The minimum quantity of pigment concentrations was recorded in Trichoderma spp and Fusarium spp as 481 and $480.5 \mathrm{U} / \mathrm{ml}-1$ respectively. Blue light induced the maximum pigment concentration of $510.5 \mathrm{U} / \mathrm{ml}-1$ in Alternaria spp. The minimum of $347.5 \mathrm{U} / \mathrm{ml}-1$ concentrations was recorded in Trichoderma spp. White light followed by blue light was in maximum pigment production. The least amount of pigment was recorded in Trichoderma spp. Green light enhanced the pigment production as $466.5 \mathrm{U} / \mathrm{ml}-1$ of concentration by Alternaria spp followed by $M$. purpureus. A moderate amount of pigments was recorded in Aspergillus spp and Fusarium spp as $388 \mathrm{U} / \mathrm{ml}-1$ and $356.5 \mathrm{U} / \mathrm{ml}-1$ respectively. The minimum quantity of pigment was recorded in Trichoderma spp. Yellow light recorded the maximum of 403.5 U/ml-1 concentration by $M$. purpureus followed by Alternaria spp. The minimum quantity $265.5 \mathrm{U} / \mathrm{ml}-1$ of pigments was produced by Fusarium spp. About 426 U/ml-1 concentration as a maximum in Alternaria spp followed by the concentration of $327 \mathrm{U} / \mathrm{ml}-1$ $M$. purpureus were noticed in red light.

The minimum quantity (212 U/ml-1) of pigment was recorded in Fusarium spp. It is evident from the results that pigment production was significantly increased when incubated under darkness followed by unscreened white light. Red light caused a reduction in pigment production.

It may be concluded that incubation of fungal cultures under darkness favored biomass production and pigment production. Blue and green light also supported pigmentation and biomass production in the four fungi. Physiochemical characterization of pigments-

\section{Effect of temperature on the stability of pigments}

The following Table 6 shows that all the pigments from selected fungi were stable at temperature of $50^{\circ} \mathrm{C}, 70^{\circ} \mathrm{C}$. In $120^{\circ} \mathrm{C}$ and dry heat (above $120 \mathrm{oC}$ ), there was a slight decomposition of pigments. Pigments of $M$. purpureus and Trichoderma spp were highly stable in all the temperature tested except dry heat. 
Table.1 Diversity of pigment producing fungi isolated from the soil samples

\begin{tabular}{|c|l|c|}
\hline S. No & Name of the fungal strain & No of isolates \\
\hline $\mathbf{1 .}$ & Fusarium $\mathrm{spp}$ & 6 \\
\hline $\mathbf{2 .}$ & Monascus $\mathrm{spp}$ & 6 \\
\hline $\mathbf{3 .}$ & Alternaria $\mathrm{spp}$ & 1 \\
\hline $\mathbf{4 .}$ & Armillaria spp & 2 \\
\hline $\mathbf{5 .}$ & Aspergillus Flavus & 3 \\
\hline $\mathbf{6 .}$ & Aspergillus niger & 5 \\
\hline $\mathbf{7}$ & Rhizopus oryzae & 2 \\
\hline $\mathbf{8 .}$ & Trichoderma spp. & 5 \\
\hline & Grand Total & 30 \\
\hline
\end{tabular}

Table.2 Effect of different $\mathrm{pH}$ on the biomass production

\begin{tabular}{|l|l|l|l|l|l|l|l|}
\hline $\begin{array}{l}\text { S. } \\
\text { No }\end{array}$ & pH & & \multicolumn{3}{|l|}{$\begin{array}{l}\text { Biomass production }\left(\mathbf{g ~}^{-\mathbf{1}} \text { dry weight /5 }\right. \\
\text { day) }\end{array}$} & \\
\hline & & M. purpureus & Alternaria & Fusarium & Aspergillus & Trichoderma \\
\hline 1. & 4.0 & 4.25 & 4.13 & 2.17 & 3.16 & 3.75 \\
\hline 2. & 5.0 & 6.02 & 5.20 & 3.68 & 4.16 & 5.10 \\
\hline 3. & 6.0 & 6.56 & 4.78 & 4.79 & 4.09 & 5.46 \\
\hline 4. & 7.0 & 5.12 & 3.74 & 3.68 & 3.26 & 3.60 \\
\hline 5. & 8.0 & 4.12 & 3.41 & 2.18 & 3.10 & 3.76 \\
\hline 6. & 9.0 & 3.14 & 2.96 & 1.36 & 2.12 & 2.41 \\
\hline
\end{tabular}

Table.3 Effect of temperature on the biomass production

\begin{tabular}{|r|l|r|r|r|r|r|}
\hline S. No & Temp & & \multicolumn{4}{|c|}{ Biomass production (g 1 $\mathbf{1}^{-1}$ dry weight /5 day) } \\
\cline { 2 - 7 } & $\left({ }^{\circ} \mathbf{C}\right)$ & M. purpureus & P. farinosus & E. nidulans & F.moniliforme & P. pupurogenum \\
\hline 1 & 20 & 3.36 & 3.63 & 3.36 & 2.10 & 3.63 \\
\hline 2 & 28 & 5.51 & 4.42 & 3.96 & 3.14 & 4.12 \\
\hline 3 & 37 & 2.90 & 2.26 & 2.13 & 2.44 & 2.08 \\
\hline
\end{tabular}

Table.4 Effect of sucrose concentration on the extracellular pigment production

\begin{tabular}{|c|r|r|r|r|r|}
\hline Sucrose \% & & \multicolumn{4}{|c|}{ Intracellular pigment production in units / U ml } \\
\hline & M. purpureus & Alternaria & Fusarium & Aspergillus & Trichoderma \\
\hline 1 & 17.0 & 27.0 & 51.0 & 15.0 & 78.2 \\
\hline 2 & 11.3 & 38.0 & 61.0 & 20.1 & 98.2 \\
\hline 3 & 12.8 & 52.6 & 72.0 & 29.8 & 112.2 \\
\hline 4 & 20.1 & 60.1 & 86.0 & 30.1 & 120.1 \\
\hline 5 & 30.1 & 67.0 & 89.0 & 41.1 & 134.0 \\
\hline 6 & 42.4 & 75.0 & 93.0 & 62.2 & 126.0 \\
\hline 7 & 32.0 & 59.0 & 76.0 & 44.0 & 102.0 \\
\hline
\end{tabular}


Table.5 Effect of light on the biomass production

\begin{tabular}{|l|c|c|c|c|c|}
\hline Light & \multicolumn{3}{|c|}{$\begin{array}{l}\text { Biomass production (g 1 } \\
\text { I5 day) }\end{array}$} & \\
\hline & M. purpureus & Altrnaria & Fusarium & Aspergillus & Trichoderma \\
\hline Darkness & 7.46 & 7.26 & 5.26 & 7.17 & 6.71 \\
\hline (No light) & & & & & \\
\hline White (Mixed & 7.14 & 7.46 & 6.14 & 6.79 & 6.14 \\
\hline unscreened) & & & & & \\
\hline Blue & 5.36 & 5.14 & 4.54 & 5.14 & 4.78 \\
\hline Green & 6.44 & 6.35 & 4.63 & 6.17 & 4.56 \\
\hline Yellow & 5.16 & 5.41 & 3.74 & 5.14 & 3.70 \\
\hline Red & 4.36 & 5.49 & 3.78 & 5.16 & 3.74 \\
\hline
\end{tabular}

Table.6 Thermal stability of pigment

\begin{tabular}{|l|c|c|c|c|c|}
\hline \multirow{2}{*}{ Treatments } & \multicolumn{4}{|l|}{ Percent stability after treatment } & \\
\cline { 2 - 5 } & $\begin{array}{c}\text { M. } \\
\text { purpureus }\end{array}$ & $\begin{array}{c}\text { Alternari } \\
a\end{array}$ & Fusarium & Aspergillus & Trichoderma \\
\hline \multirow{2}{*}{$\mathbf{7 0}^{\mathbf{0}} \mathbf{C}$} & & & Heat treatment & & \\
\hline & 96.7 & 98.5 & 96.5 & 97.2 & 93.6 \\
\hline $\mathbf{1 0 0}^{\mathbf{0}} \mathbf{C}$ & 92.4 & 95.5 & 87.2 & 86.3 & 84.1 \\
\hline $\mathbf{1 2 0}^{\mathbf{0}} \mathbf{C}$ & 89.2 & 88.2 & 81.8 & 73.9 & 74.6 \\
\hline (Autoclave) & & & & & \\
\hline Dry heat & 71.5 & 76.4 & 71.6 & 65.7 & 75.2 \\
\hline (Microwave & & & & & \\
\hline oven 1 min) & & & & & \\
\hline
\end{tabular}

Table.7 pH stability of pigment

\begin{tabular}{|l|c|c|c|c|c|c|c|c|c|c|}
\hline & \multicolumn{2}{|c|}{ M. purpureus } & \multicolumn{2}{l|}{ Alternaria } & \multicolumn{2}{l|}{ Fusarium } & \multicolumn{2}{l|}{ Aspergillus } & \multicolumn{2}{|c|}{ Trichoderma } \\
\hline pH & $\mathbf{2}$ & $\mathbf{9}$ & $\mathbf{2}$ & $\mathbf{9}$ & $\mathbf{2}$ & $\mathbf{9}$ & $\mathbf{2}$ & $\mathbf{9}$ & $\mathbf{2}$ & $\mathbf{9}$ \\
\hline & & & & & & & & & & \\
\hline $\mathbf{1 5}$ min & 93.5 & 100.0 & 98.5 & 99.2 & 93.0 & 96.6 & 95.8 & 95.8 & 97.6 & 98.4 \\
\hline $\mathbf{3 0}$ min & 92.4 & 98.8 & 94.1 & 97.0 & 93.0 & 95.3 & 93.1 & 89.0 & 95.2 & 96.8 \\
\hline & & & & & & & & & & \\
\hline
\end{tabular}

Table.8 Photolytic stability of pigment

\begin{tabular}{|l|r|r|r|r|r|}
\hline Light treatment & M. purpureus & Alternaria & Fusarium & Aspergillus & Trichoderma \\
\hline Sunlight & 90.3 & 91.1 & 83.7 & 95.8 & 80.1 \\
\hline Fluorescent light & 98.9 & 99.2 & 97.6 & 95.8 & 99.2 \\
\hline UV light & 92.4 & 88.2 & 82.5 & 87.6 & 89.6 \\
\hline
\end{tabular}


Table.9 Thin layer chromatography separation of pigments

\begin{tabular}{|l|l|r|r|l|}
\hline S. No & Source of pigments (Fungi) & Band No & Rf value & Color of the bands \\
\hline $\mathbf{1}$ & M. purpureus & 1 & 0.98 & Red \\
\hline & & 2 & 0.96 & Pink \\
\hline & & 3 & 0.78 & Orange \\
\hline & & 4 & 0.42 & Pink \\
\hline $\mathbf{2}$ & Alternaria & 1 & 0.21 & Yellow \\
\hline & & 2 & 0.89 & Yellow \\
\hline & & 3 & 0.54 & Orange \\
\hline $\mathbf{3}$ & Fusarium spp & 1 & 0.67 & Red \\
\hline & & 2 & 0.99 & Red \\
\hline & & 3 & 0.98 & Yellow \\
\hline $\mathbf{4}$ & Aspergillus spp & 1 & 0.96 & Yellow \\
\hline & & 2 & 0.67 & Red \\
\hline $\mathbf{5}$ & Trichoderma spp & 1 & 0.53 & Red \\
\hline & & 2 & 0.11 & Red \\
\hline & & 3 & 0.54 & Pink \\
\hline & & 4 & 0.65 & Orange \\
\hline & & 5 & 0.42 & Red \\
\hline & & 6 & 0.23 & Red \\
\hline & & 7 & 0.76 & Yellow \\
\hline & & & \\
\hline & & & & \\
\hline
\end{tabular}

Solvent system used is chloroform: methanol (1:3)

Table.10 Natural, "Green" dyes produced at Bench-Scale level

\begin{tabular}{|l|l|l|l|}
\hline Chemical Name & Type of Dye & Produced from & Classification \\
\hline Indigo & Indigoid & Escherichia coli & Bacteria \\
\hline Indigo & Indigoid & Nocardia globerula & Bacteria \\
\hline Saffron & CI Natural Yellow 6 & Crocus sativus L & Plant \\
\hline Chrysophanol & Anthraquinone & Curvularia lunata & Fungus \\
\hline Helminthosporin & Anthraquinone & Curvularia lunata & Fungus \\
\hline Cyonodontin & Anthraquinone & Curvularia lunata & Fungus \\
\hline
\end{tabular}


Fig.1-5 Screening of pigment producing fungi

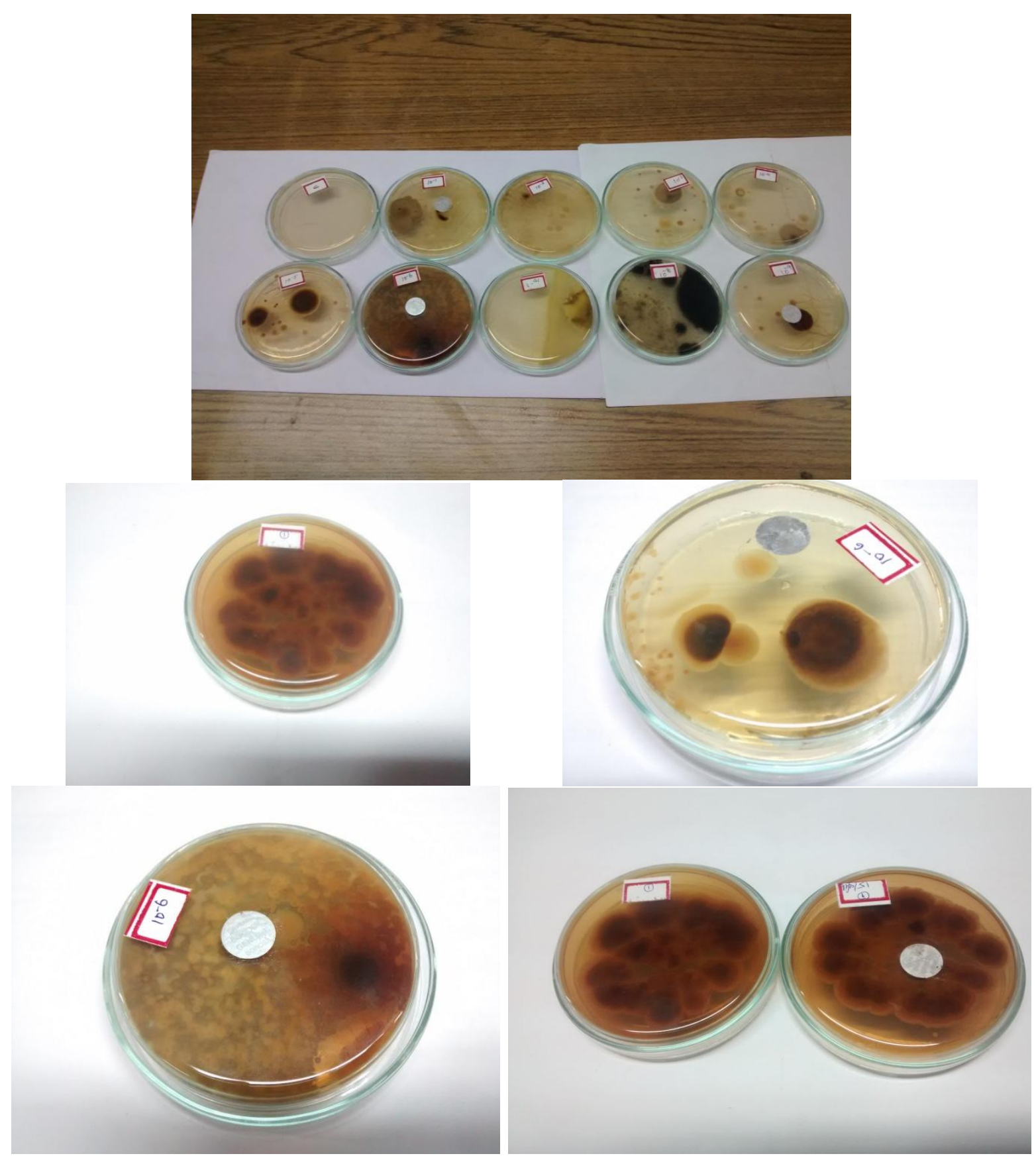

\section{Effect of pH on stability of pigment}

Table 7 shows the stability of the pigment at different $\mathrm{pH}$ levels. In general, fungal pigments were quite stable at alkaline and acid $\mathrm{pH}$. It may be inferred that $\mathrm{pH}$ caused little damage to the pigments.

\section{Effect of light on the stability of pigment}

Table 8 shows different sources of light like sunlight, UV light and fluorescent light were tested for the stability analysis. Exposure to fluorescent light did not affect pigment stability. However under UV and sunlight there was slight reduction in stability. 


\section{Purification and characterization of pigments}

Pigments excreted out in the liquid fermentors were collected and purified. The purification was carried out by HPLC, Column and Thin Layer Chromatography from culture filtrate and by solvent extraction procedures as described earlier and characterization was done with help of using, Spectrophotometer, GC-MS, IR and NMR spectroscopy. HPLC analysis was carried out to know the retention time and similarities in the pigments. The results of the analysis are given in figure 1-5. The fungi $M$. purpureus exhibited peaks at 12.75 and 13.00 minutes and produce 2 distinct peaks. Alternaria spp recorded peaks at $7.0 \mathrm{~min}, 9.75 \mathrm{~min}$, and 12.10 and 13.00 minutes produced 4 distinct peaks. Fusarium spp showed peaks at 7.0, 8.25, 11.75, 12.0, 13.15 minutes and exhibited 5 distinct peaks. Aspergillus spp elaborated peak at 2.25, 7.0, 10.0, 11.10, 12.10, 13.00 minutes and showed 7 distinct peaks. Trichoderma spp revealed 5 distinct peaks. It may be summed up that all the five species of fungi produced distinct pigments separable into several fractions. Thin layer chromatography-The fungal pigments were partly purified using Thin Layer Chromatography, purified pigments of fungi were resolved into discrete bands of different colors. Their Rf values are presented in the Table 9.

Pigments form Monascus purpureus recorded 4 bands depicting different colors of Red -1 band, Pink -2 bands and Orange -1 band. Pigments form Alternaria spp displayed three distinct bands of yellow-2 bands and orange- 1 band. Pigments of Fusarium spp were separable in to three individual bands with red-2 bands and yellow-1band. The crude pigments from the fungus Aspergillus spp upon TLC showed two distinct bands of dark Yellow-1 band and Red- 1 band colors. Interestingly, pigments from Trichoderma spp exhibited 7 separate bands on TLC plates. They were red-4 bands, Yellow-1 band, Pink1 band and Orange- 1 band, pigments. From this analysis, it may be inferred that predominating pigments in the four isolates were Yellow and Red. Extract identification The UV spectrum, showed the presence of valuable color pigments produced from the five fungi. However, the initial TLC (Si gel, methanol and chloroform 10:3) showed the different types of pigments. On the other hand, the fungi did not show the same pigments detected in the other fungi ( $\mathrm{Si}$ gel, chloroform: methanol 1:3). The colored methonolic fraction yielded orange, pink, red and yellow pigments using combined normal and reversed phase chromatography Spectrophotometric scanning of pigments In general, all the pigments studied had their maximum absorbance in the visible range. Between $300 \mathrm{~nm}$ to $500 \mathrm{~nm}$, there was maximum absorption in all the color pigments. Pigments of $M$. purpureus, Alternaria spp, Fusarium spp and Trichoderma spp exhibited absorption maximally at $490 \mathrm{~nm}$, for Aspergillus spp exhibited absorption peak at $400 \mathrm{~nm}$. Absorption spectrum indicated that, the pigments contained other interesting compounds used in textile and leather industry. Mass spectrum analysis: The Gas Chromatography- Mass spectrometry of the fungi $M$. purpureus, Alternaria, Fusarium spp, Aspergillus spp and Trichoderma spp Red, brown and yellow pigment showed a large peak at $\mathrm{m} / \mathrm{z} 365.2,455.5,387.4,462.8$ and 265.5 that is consistent with the $(\mathrm{M}+\mathrm{H})^{+}$ ion of the compound. Infrared spectrum analysis: The infrared spectrum of red, brown and yellow produced by $\mathrm{M}$ purpureus, Alternaria spp, Fusarium spp, Aspergillus spp and Trichoderma spp pigment. The main absorbance peaks included 3303.7, 2928.04, 2733.71, 1715.16, 1596.89, 1453.97, 1210.01, 1050.02, and 791.562. The peaks at 3303.7, 1210.01, and 1050.02 suggested a hydroxide 
bond in molecules. The peaks at 23303.7 and 1596.89 indicated that there might be $\mathrm{NH}$ groups present. The peak at 2928.04 was very sharp, indicating that there were multiple $\mathrm{CH} 2$ groups present. The peaks at 1715.16, 1596.89 and 1453.97 indicate the presence of benzol structure and $\mathrm{CH} 3$ group.

Since long time, a variety of colors, have been used in dying of fabrics and leather. An appealing and pleasing color of fabrics and leather is an important characteristic that goes a long way with the aesthetic value and ready expectance by people. Many synthetic dyes have crept into dyeing industry in the middle of last century and assumed monopoly. Though they are cheap, fast acting, stable, attractive with innumerable shades, people have realized their ill effects. Moreover, a great deal of concern has been raised by the effects of some synthetic dyes on human health as sources of skin cancer, disorders and allergic reactions (Francalanci et al., 2001). Therefore, the trend of the day is to minimize synthetic colors and use colors of natural origin. Various parts plants, animal products, insects and naturally occurring minerals were used over hundreds of years as natural colors. Microorganisms occupy a distinct place as source of natural colors. More than bacteria, fungi display a wide range of fascinating colors. However, till recently fungi are remained unexplored for color production. This is perhaps due to their association with mycotoxins and aflatoxins. In the present study, an attempt has been made to identify species of pigment producing fungi and to make use of the color for textile and leather dying. The well-known pigments producing fungi like, Monascus purpureus has also been included. The current trend in society for 'natural' ingredients has stimulated interest in exploring novel means and sources for the biotechnological production of colorants. In this regard, exploring fungal chemical diversity is a worthwhile route for the identification of novel pigments. An intelligent screening approach for watersoluble pigments that is partly based on chemotaxonomy will provide a platform for the future construction of cell factories for the production of natural colorants. If imperative toxicological testing is carried out, fungal pigments could be accepted by the current consumer. Further research using new technologies suggests a promising future for this field of study. Fungal pigments: Characteristic pigments are produced by a wide variety of fungi. Species of Drechslera give hydroxyanthraquinones (e.g., helminthosporin (maroon, brown) (Table 10), catenarin (red), cynodontin (bronze), tritisporin (red brown); the similar compound, erytroglaucin (red), is produced by forms of Aspergillus glaucus which gives in addition auroglaucin (orange) and flavoglaucin (yellow). Among other pigments, investigations have been made on aurofurasarin (orange yellow) and rubrofusarin from Fusarium culmorum; aurantin (yellow) and oosporin (purple-brown with ferric chloride) from Chrysonilia sitophila; melanin pigments (black) from Phellinus robustus and Inonotus obliquus; 26 boletol (blue) from Boletus luridus and other species; citromycetin, chrysogenin, citrinin, fulvic acid (soluble fraction from soil under all pH's) and also yellow pigments from Penicillium. Many mycotoxins are pigmented, naphthoquinones from Penicillium and Aspergillus (Ainsworth and Bisby's, 1995). Monascus red pigment and/or yellow pigments are efficiently produced by several strains and are commercially important. (Blanc, 1998; Shin et al., 1998). Monascus purpureus was selected to study the bioconversion of whole wheat flour for the production of food colorants (Espinoza and Webb, 1998). Penicillium species that produces patulin, citrinin, palitantin and arthographol, respectively, were identified from 149 different microorganisms screened 
(Yamaji et al., 1999). A red-violet pigment was isolated from Rissula vinosa. The dyestuff industry is suffering from the increases in costs of feedstock and energy for dye synthesis and they are under increasing pressure to minimize the damage to the environment caused by the process and effluents. Thus, the industries are continuously looking for cheaper, more environment friendly routes to existing dyes. Through biotechnological techniques anthraquinones have been isolated from a number of fungi, namely, Trichoderma, Drechslera, Aspergillus, and Curvularia strains (Margalith, 1992). Fusarium oxysporum isolated from roots of diseased citrus trees produced anthraquinones with no hydroxyl substituents at the 1, 4-position, and they have an acetyl or 1-hydroxyethyl group at the 2 or 3 positions. Expensive fuelconsuming high-temperature and environmental unfriendly strong acids and alkalis of the chemical synthesis are not required. Source and isolation of pigment producing fungi: As soil is regarded as the "treasure house" of microorganisms, soil samples were collected from different parts of agricultural lands. The purpose of selecting different soil samples was to explore the biodiversity of pigment producing fungi and other fungi. The study revealed that the population of fungi was much higher in the rhizosphere soil samples than in other soils presumably due to rich organic matter content of former. Though the number of pigment producing fungi in general was low, they were in considerable numbers and diversity in forest soils. The number of fungi recorded in India exceeds 27, 000 species, the largest biotic community after insects (Sarbhoy et al., 1996). Rhizosphere soils samples, by virtue of their abundance in nutrients would provide a variety of fungi (Manoharachary et al., 2005). Screening of fungi for pigment production: Though many of the isolates of fungi were producing pigment in nature, a screening schedule was necessary to recognize the potential pigment producer. Under a given growth conditions, some of the isolates produced more quantity of extracellular pigments. The vigorous screening yielded four isolates. These isolates excreted very intense colors of red, red, brown and yellow pigments respectively. As these four isolates consistently registered very high quantity of pigment excretion, they were selected for detailed studies. Taxonomic characterization of fungal isolates: Depending on the type of compound, they serve different functionsvarying from a protective action against lethal photo-oxidations (carotenoids) to protection against environmental stress (melanins) and acting as cofactors in enzyme catalysis (flavins). Besides providing functional diversity to the host, these pigments exhibit a unique structural and chemical diversity with an extraordinary range of colors. Several characteristic non-carotenoid pigments are produced by filamentous fungi, including quinones such as anthraquinones and naphthaquinones (Medenstev et al., 1998), dihydroxy naphthalene melanin (a complex aggregate of polyketides) (Butler and Day, 1998), and flavin compounds such as riboflavin (Duran et al., 2002). Anthraquinone (octaketide) pigments like catenarin, chrysophanol, cynodontin, helminthosporin, tritisporin and erythroglaucin are produced by Eurotium spp., Fusarium.spp., Curvularia lunata and Drechslera spp (Duran et al., 2002). Yellow pigments epurpurins A to $\mathrm{C}$ were isolated from Emericella purpurea (Hideyuki et al., 1996) and azaphilone derivatives (hexaketides), falconensins $\mathrm{A}-\mathrm{H}$ and falconensones A1 and B2, are produced both by Emericella falconensis and Emericella fructiculosa (Ogasawara et al., 1997). The four newer isolates of fungi obtained in the present study were characterized. Identity of the standard cultures was confirmed by their reproductive structures with the help of key 
provided by Hawksworth and Pitt (1983). The taxonomical aspect of screening microorganisms is often de-emphasized in patents describing the structure elucidation of bioactive secondary metabolites used for drug leads and as pigments. For example, the producer of the red pigment Arpink RedTM is claimed to be produced by Penicillium oxalicum var. armeniaca, (the variety was never described), but from the description in the patent Sardaryan (2002) was of the opinion that the fungus was most likely misidentified as belonging to the genus Penicillium. The isolate (CCM 8242, unavailable for the scientific community) is described as having yellow gold colored conidia with a diameter of $15-20 \mathrm{~mm}$ and 'short' mycelium of a light green color. None of these characteristics has ever been seen in a Penicillium species (Raghukumar, 1996). Isolates were studied using moisture chamber technique.

The morophological features of the four isolates were critically examined and their taxonomic statergy were determined as Alternaria spp, Fusarium spp, Aspergillus spp and Trichoderma spp) as per the detailed description provided Alexopoulos and Mims, (1988) Cultural and physiological characters of the selected fungi: In order to recognize the optimum growth conditions for maximum pigment production, the selected fungi were grown at different, $\mathrm{pH}$ levels, temperature, agitation, with various sources of carbon, nitrogen and light sources. The pigments isolated in the present study were tested for their stability at different temperatures $(50,70$ and $120^{\circ} \mathrm{C}$ ), different $\mathrm{pH}$ levels $(\mathrm{pH} 2.0$ to 9.0). Sun light sources (UV, fluorescent and sunlight) and with addition of different chemical preservatives. The results have clearly shown that the pigments were quite stable not only under normal conditions but also at extreme conditions. There was no decomposition or degradation of pigments on extreme temperature, $\mathrm{pH}$, light as reported earlier by Lee et al., (1995). Separation of pigments from the culture media was attempted by two processes, (i) air drying and (ii) solvent extraction procedures.

In the present study, the cell free culture filtrate obtained through filtration of culture broth was air dried under bright sun light and the crude pigment recovered. Pigments were further purified with $\mathrm{CCl}_{4}$. These solvents are found suitable for all the five fungal pigments. The crude preparation of pigments were done and stored. The mycelial pigments could be extracted with hot methyl alcohol (Blanc et al., 1994), freeze dried mycelial sonication and liquid nitrogen drying followed by ethyl alcohol extraction (Martinkova et al., 1999). In the present study, the extracted crude pigments were separated by thin layer chromatography (TLC) into distinct bands and the bands were eluted and analyzed further (Blanc et al., 1994, Martinkova et al., 1999). The partially purified pigments were anlayzed using HPLC to detect the individual compounds. The methods suggested by Blanc et al., (1994) were followed by the HPLC analysis. It can be concluded that From the foregoing summary it becomes supply amply clear that $M$. purpureus and other potential fungi like Alternaria spp, Fusarium spp, Aspergillus spp and Trichoderma spp offers good scope for industrial production of biocolorants.

\section{Acknowledgement}

Generous funding by University Grant Commission (UGC) under minor research project is gratefully acknowledged. I also wish to acknowledge constant encouragement received from the Principal and Management of Loyola College, Chennai-34.

\section{References}

Ainsworth and Bisby's, 1995. Dictionary of 
the Fungi, D.L. Hawksworth, P.M. Kirk, B.C. Sutton and D.N. Pegler (Eds) 8th ed., Wallingford, CAB International, pp 616.

Ainsworth, G.C., F.K. Sparrow and A.S. Sussman, 1973. The fungi: An Advanced Treatise. Academic Press, New York.

Alexopoulos C.J and C.W Mims, 1988. Introductory Microbiology, (Edn). Wiley eastern Ltd. (Ed), pp.3- 586.

Barnett, H. L, 1958. Illustrated genera of imperfect fungi. Burgeus Publication Co., Minneapolis, Min. p. 218.

Blanc, P.J., M.O. Loret, A.L. Samterre, A. Pareilleus, D. Prome, J. P. Laussac and G.Goma, 1994. Pigments of Monascus. J. Food Sci., 59: 862 - 865.

Blanc. P., 1998. Les pigments rouges de Monascus. Bio futur, 183: 34-36.

Butler M. J. and A. W. Day, 1998. Fungal melanins: a review. Can. J. Microbiol., 44: 1115-1136.

Cappuccino, J.G and N. Sherman. 1996. Cultivation and morphology of molds. In: Microbiology, A Laboratory Manual, The Benjanin / Cummings Publ. Co. Menio Park. pp. 201 - 202.

Dennis, R.W.G. 1968. British Ascomycetes. J. Cramer Lehre, p. 455

Diana D.S., M. Moresi, G. Anna Maria and P. Maurizio, 2005. Assessment of the dyeing properties of pigments from Monascus purpureus. J. Chem. Technol. Biotechnol., 80:1072-1079.

Duran N., M. F. S. Tixeira, R. De Conti and E. Esposito, 2002. Ecological-friendly pigments from fungi. Crit Rev. Food Sci. Nutr., 42:53-66.

Espinoza R. M. D and C. Webb, 1999. Bioconversion of whole wheat flour for production of food colorants, chem. Res. Event. Two Day Symp, 7481.Chem. Abstr, 129: 184

Francis F.J., 1987. Lesser-known food colorants. Food Technol., 41: 62-68.
Gilman, J.C., 1957. A manual of soil fungi. Oxford and IBH Publishing Co., New Delhi p. 450.

Hamlyn P.F, 1995. The impact of biotechnology on the textile industry. Text Mag; 6-10

Hawksworth, D.L. and J.I. Pitt, 1983. A new taxonomy for Monascus species based on cultural and microscopical characters. Australian J. Bot., 31: 51 61

Lee, Y.K and D.C. Chen. 1998. Application of Monascus pigment as food colourant. Symposium on Monascus culture and applications, Institut Nationals des Sciences Apliquees de Toulouse, Toulouse, Frankreich, France, July 8 10.

Lee, Y.K., D.C. Chen, S. Chauvathatcharin, T. Seki and T. Yoshida, 1995. Production of Monascus pigment by a solid-liquid state culture method. J. Fern. Bioeng, 79: 516 - 518.

Lin, C and H. Iizuka. 1982. Production of extracellular pigment by a mutant of Monascus kaoliang sp. nov. Appl. Microbiol. Biotechnol, 43: 671- 676.

Manoharachary, C., K. Sridhar, S. Reena, A. Alok, T.S. Suryanarayanan, R. Seema and B.N Johri, 2005. Fungal biodiversity: Distribution, conservation and prospecting of fungi from India, current science, 89: 1.

Martinkova, L., P. Juslova, V. Kren, Z. Kucerova, V. Havlicek, P. Olsovsky, O. Hovoka, B. Rihova, D. Vasely, D. Vesela, J. Ulrichova and V. Prikrylova, 1999. Biological activities of oligoketode produced by Moascus purpureus. Food Add Contamint ants, 16: $15-24$.

Medenstev, A. G and V.K. Akimenko, 1998. Naphthoquinone metabolites of the fungi. 16: 21-27.

Pattnaik, U., 1997. Biocolours: new generation additives for food. Indian 
Food Industry. Phytochemistry, 47:935959.

Sarbhoy, A. K., D.K. Agarwal and J.L. Varshney, 1996. Fungi of India 19821992, CBS Publishers and Distributors, New Delhi, p. 350.

Sardaryan, E., 2002. Strain of the microorganism Penicillium oxalicum var. Armeniaca and its application. US Patent, 6, 340, 586 B1.

Sengupta S and B. R. M. Singh, 2003. Natural, "Green" Dyes for the textile industrytoxics use reduction institute university research in sustainable technologies program, Technical Report No. 57, page No, 1-12.

Shin C. S., 1998. Productivity increase of
Monascus pigments, Jpn. Kokai Tokkyo Koho JP, 10004988; Chem. Abstr., 28: 101172.

Taylor G. W., 1986. Natural dyes in textile applications, Rev Prog Coloration 16: 53-61.

Warcup, W.H., 1950. The soil plate method for isolation of fungi from soil. Nature, 166: 117.

Yamaji K., Y. Fukushi, Y. Hashidoko, T. Yoshida and S. Tahara, 1999. Characterization of antifungal metabolites produced by Penicillium species isolated from seeds of Picea glehnii. J. Chem. Ecol., 25:1643-1653.

\section{How to cite this article:}

Carol Andrew Pereira. 2019. Soil Fungi as Potential Source of Eco-Friendly Colorants. Int.J.Curr.Microbiol.App.Sci. 8(08): 1333-1348. doi: https://doi.org/10.20546/ijcmas.2019.808.157 